\title{
Rupture process for micro-earthquakes inferred from borehole seismic recordings
}

\author{
Taka'aki Taira $^{1} \cdot$ Douglas S. Dreger $^{1} \cdot$ Robert M. Nadeau $^{1}$
}

Received: 11 August 2014 / Accepted: 14 June 2015 / Published online: 7 July 2015

(C) The Author(s) 2015. This article is published with open access at Springerlink.com

\begin{abstract}
We investigate the spatial extent of rupture and variability in fault slip for micro-earthquakes by inverting seismic moment rate functions derived from empirical Green's function deconvolution. By using waveforms from an array of borehole seismometers, we determine the spatial distributions of fault slip for $M 3+$ earthquakes that occurred along the Hayward fault in central California and identify a variety of slip behaviors including subevents, directivity, and high stress drop. The $2013 M_{\mathrm{w}} 3.2$ Orinda earthquake exhibits a complex rupture process involving two subevents with northwest and up-dip directivity. The two subevents release 43 and $18 \%$ of the total seismic moment $\left(6.7 \times 10^{13} \mathrm{~N} \mathrm{~m}\right)$, and their inferred peak stress drops are 18 and $8 \mathrm{MPa}$. The $2011 M_{\mathrm{w}} 4.0$ Berkeley and $2012 M_{\mathrm{w}} 4.0$ El Cerrito earthquakes are marked by high stress drop. The inferred peak and mean stress drops are about 100-130 and $40 \mathrm{MPa}$, respectively, which suggests that there are locally high levels of fault strength on the Hayward fault. Our finite-source modeling suggests that the radiation efficiency determined for these two earthquakes is very low $(<0.1)$ and implies that most energy is dissipated during the earthquake rupture process.
\end{abstract}

Keywords Earthquake rupture - Earthquake stress drop · Finite-source rupture inversion $\cdot$ Hayward fault

Electronic supplementary material The online version of this article (doi:10.1007/s00531-015-1217-8) contains supplementary material, which is available to authorized users.

Taka'aki Taira

taira@berkeley.edu

1 Berkeley Seismological Laboratory, University of California, Berkeley, CA 94720, USA

\section{Introduction}

The connection between the strength of tectonic faults and earthquake rupture is central to studies of the physics of earthquakes. Earthquake stress drop is one of the source parameters of the earthquake rupture process that can be obtained from observed waveforms. The resultant stress drop reflects the state of stress and the strength of the rocks in which the faulting occurs. Previous studies have shown spatial and temporal variations in stress drop (e.g., McGarr and Fletcher 2002; Allmann and Shearer 2007, 2009; Baltay et al. 2011; Chen and Shearer 2011). Allmann and Shearer (2007) have systematically examined the spatial distribution of earthquake stress drop along the creeping section of the San Andreas fault, California, and found that high-stress-drop earthquakes occurred near the hypocenter of the 2004 magnitude $(M)$ 6.0 Parkfield earthquake.

Another important aspect of the earthquake stress drop is its spatial heterogeneity within rupture areas. Dreger et al. (2007) revealed that micro-earthquakes $(M \sim 2)$ in the transitionally creeping Parkfield segment of the San Andrea fault have complex slip distributions leading to locally high-peak stress drops (70-90 MPa), while the stress drop averaged over the entire rupture patch is only about $10 \mathrm{MPa}$. The averaged stress drop obtained is in good agreement with the estimated stress drop inferred from corner frequency measurements (Imanishi and Ellsworth 2006), and the peak value is in good agreement with estimates from Nadeau and Johnson (1998) inferred from recurrence intervals and geodetic loading information after accounting for differences in the rigidity used in that study. This would indicate that estimates of stress drop using corner frequency measurements are sensitive to the stress drop averaged over the rupture area, while the finite-source modeling resolves the detailed spatial distribution of stress 
Table 1 Hayward-fault target and empirical Green's function (eGf) earthquakes

\begin{tabular}{|c|c|c|c|c|c|c|c|}
\hline Event $^{\mathrm{a}}$ & Date & Time (UTC) & Latitude & Longitude & Depth (km) & $M$ & NCSS event ID \\
\hline BK11 & October 20, 2011 & 21:41:04.40 & 37.86506 & -122.24066 & 8.16 & 4.0 & 71667366 \\
\hline BK11-eGf & August 11, 2012 & $23: 48: 36.24$ & 37.86419 & -122.24148 & 7.27 & 1.9 & 71829981 \\
\hline $\mathrm{EC} 12$ & March 5, 2012 & $13: 33: 20.44$ & 37.93364 & -122.29282 & 8.34 & 4.0 & 71746766 \\
\hline EC12-eGf & March 12, 2012 & 03:24:31.91 & 37.93512 & -122.29203 & 8.43 & 2.0 & 71746615 \\
\hline OR13-1 & October 7, 2013 & 04:26:08.25 & 37.89200 & -122.22168 & 6.52 & 3.0 & 72082611 \\
\hline OR13-1-eGf & October 24, 2013 & $04: 47: 15.62$ & 37.89331 & -122.22200 & 6.48 & 1.6 & 72094286 \\
\hline OR13-2 & October 15, 2013 & 08:07:26.51 & 37.88887 & -122.22022 & 6.59 & 3.2 & 72087796 \\
\hline OR13-2-eGF & October 15,2013 & $06: 23: 14.00$ & 37.88997 & -122.22017 & 6.45 & 1.7 & 72087746 \\
\hline
\end{tabular}

Earthquake origin times and hypocentral parameters from the double-difference earthquake catalog from Waldhauser and Schaff (2008) while magnitudes $(M)$ determined by the Northern California Seismic System (NCSS). Also listed are the NCSS event ID

${ }^{a}$ BK11, the October 20, 2011, $M_{\mathrm{w}} 4.0$ Berkeley; EC12, the March 5, 2012, $M_{\mathrm{w}} 4.0$ El Cerrito earthquake; OR13-1, the October 7, $2013, M_{\mathrm{w}} 3.0$ Orinda earthquake; and OR13-2, the October 15, 2013, $M_{\mathrm{w}} 3.2$ Orinda earthquake

drop within the rupture interior. Robust estimates of both average stress drop and stress change heterogeneity during earthquake rupture are important for a better understanding of both rupture dynamics and faulting mechanics.

It should be also noted that only a few studies have examined the spatial distributions of fault slip (and stress) for smaller earthquakes $(M \leq 4)$ (e.g., Mori 1993; Yamada et al. 2005; Dreger et al. 2007; Uchide and Ide 2010). This is because high-quality seismograms from local networks, especially borehole seismometers are needed to capture high-frequency waves $(>1 \mathrm{~Hz})$ for exploring the rupture process of such small earthquakes. Here, we document the high-resolution imaging of the kinematic finite-source rupture models for four recent $M 3+$ Hayward fault (HF) earthquakes (hereafter called the target earthquakes) listed in Table 1. We make use of the low-noise recordings from a dense array of $8-12$ borehole stations that provide a unique opportunity for investigating the rupture process of the HF micro-earthquakes. Using an empirical Green's function approach, we extract moment rate functions for the target $\mathrm{HF}$ earthquakes and examine their spatial slip distributions.

\section{Data and analysis}

\section{Hayward fault network}

The HF in the San Francisco Bay Area of California is one of the major strands of the San Andreas fault system, extending in length for about $70 \mathrm{~km}$. Crustal deformation along the HF is characterized by a wide variety of fault slip behaviors from aseismic creep (Schmidt et al. 2005) to stick-slip earthquakes including the 1868 HF earthquake that had an inferred seismic moment magnitude $\left(M_{\mathrm{w}}\right)$ of 6.8 (e.g., Lienkaemper et al. 2012). To explore the rupture processes for the four target earthquakes
(Table 1), we make use of borehole seismograms from the Hayward fault network (HFN). This network is composed of an array of borehole instrumentation deployed along the HF to complement the regional surface broadband and short-period seismic networks for improving monitoring capabilities of the spatial and temporal evolution of micro-seismicity in the area (Uhrhammer and McEvilly 1997). It also contributes operational data to the Northern California Seismic System (NCSS) for realtime seismic monitoring and long-term hazards mitigation and enables a significantly lower detection threshold for micro-earthquakes.

In 1995-1997, the HFN was initially deployed through a cooperative effort between the U.C. Berkeley campus, the U.C. Berkeley Seismological Laboratory (BSL), U.S. Geological Survey, California Department of Transportation (Caltrans), and Lawrence Berkeley and Lawrence Livermore National Laboratories. Both free-field and non-free-field (i.e., located at the regions major bridges) borehole stations were installed. Coverage and density of the HFN stations have grown through time. During 2001-2006, five borehole seismometers were installed along the San Andreas fault system in the San Francisco Bay Area through the integrated instrumentation program for broadband observations of plate boundary deformation called the mini-Plate Boundary Observatory (miniPBO) project (Murray et al. 2002). These 5 sites and 2 additional sites from the NSF PBO project were folded into the HFN in 2006-2007 and 2010, respectively. During 2005-2009, three additional HFN sites were installed with support from Caltrans. As of January 2015, 19 borehole stations are operational, which provides an unprecedented high-resolution coverage suitable for earthquake source studies of HF earthquakes (Fig. 1). Of the 14 M 3+ events that have occurred during 2008-2014 at a central part of the HFN where the station coverage 
(a)

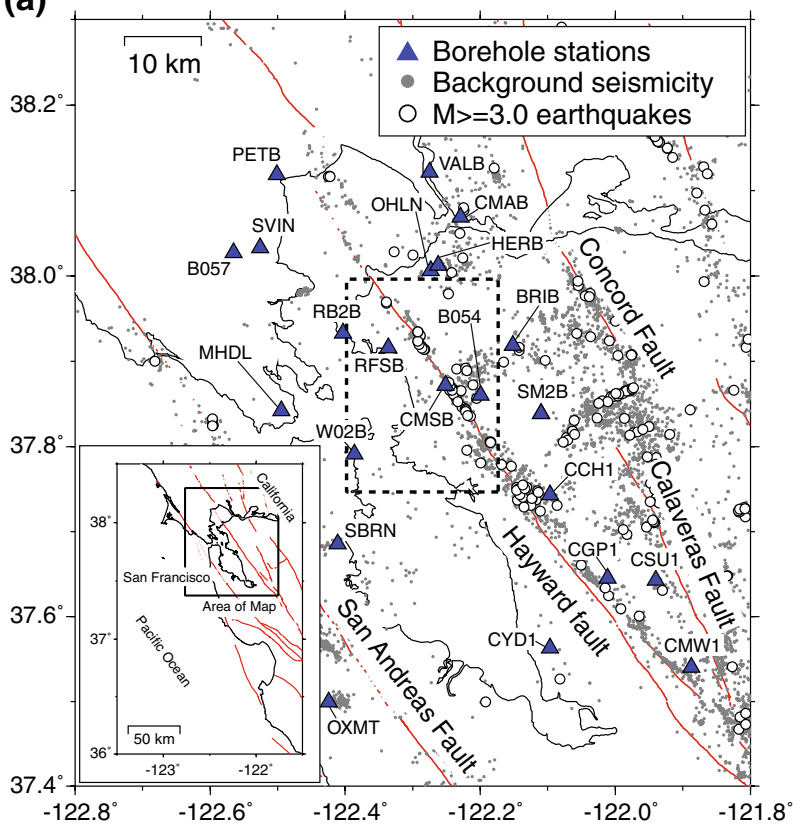

(b)

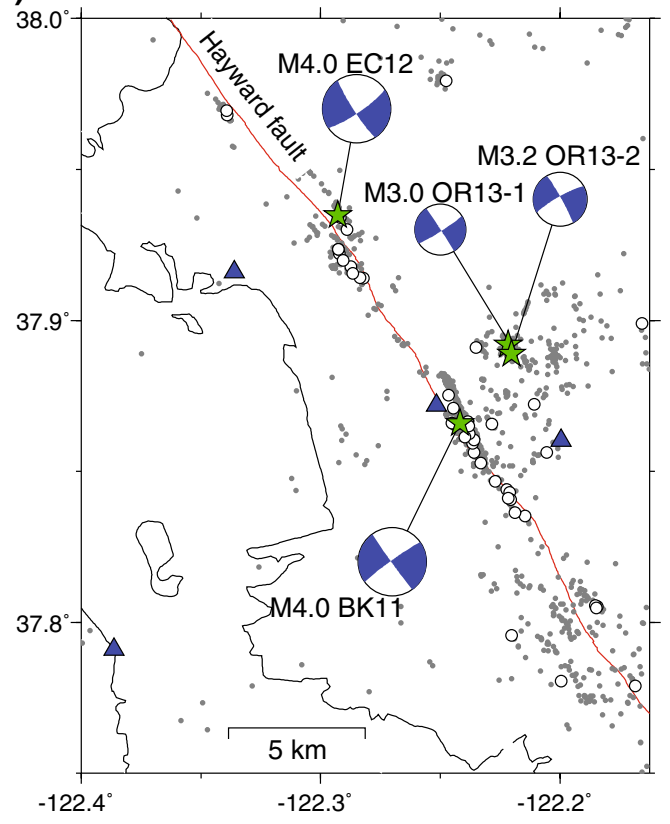

Fig. 1 a Map view of the background seismicity (1990-2013) around the San Francisco Bay Area of central California. Gray dots are earthquake locations relocated by Waldhauser and Schaff (2008). Open circles are $M \geq 3.0$ earthquakes that occurred during this time interval. Blue triangles are the locations of the borehole sites of the Hayward fault network. Red lines are the surface traces of the faults (U.S. Geological Survey and California Geological Survey, Quaternary fault and fold database for the USA, 2010, http://earthquake.

is excellent (the dashed rectangle in Fig. 1a), we were only able to find nearby smaller earthquakes suitable for empirical Green's function analysis for the four target earthquakes studied here.

The HFN stations are typically equipped with threecomponent short-period geophones (the natural frequency is either 2.0 or $4.5 \mathrm{~Hz}$ ) and accelerometers at a depth of 30-200 $\mathrm{m}$. The seismic data are sampled at up to $500 \mathrm{~Hz}$, although the majority of data used are sampled at $100 \mathrm{~Hz}$. The HFN borehole sensors serve to notably reduce the environmental noise (e.g., car traffic, ocean surf) in the frequency range of interest (i.e., 0.1$30 \mathrm{~Hz}$ ). A few sites are installed near Bay Area bridges for monitoring input ground motions affecting those structures (e.g., stations PETB and VALB). At these sites, the background noise levels are comparable to or larger than those from most surface stations. Seismic data collected by the HFN stations are archived at the Northern California Earthquake Data Center (NCEDC), and all waveform data used in this study were extracted from the NCEDC (2014). More detailed information about the HFN is available at http://seismo.berkeley.edu/ bdsn/hfn.overview.html and http://seismo.berkeley.edu/ docs/2014anrep_pt2.pdf. usgs.gov/hazards/qfaults/). The map insert shows our target area (solid rectangle). b Enlarged view of the seismicity within the dashed rectangle shown in a. Green stars are the $M \geq 3.0$ Hayward fault earthquakes analyzed (BK11, the October 20, 2011, $M_{\mathrm{w}} 4.0$ Berkeley; EC12, the March 5, 2012, $M_{w} 4.0$ El Cerrito earthquake; OR13-1, the October 7, 2013, $M_{\mathrm{w}} 3.0$ Orinda earthquake; and OR13-2, the October $15,2013, M_{\mathrm{w}} 3.2$ Orinda earthquake)

\section{Moment rate function}

We employ an empirical Green's function (eGf) deconvolution approach (Mori and Hartzell 1990) to extract the moment rate function (MRF) for the target $M 3+\mathrm{HF}$ earthquakes. In this approach, the MRF of a larger target earthquake is obtained by deconvolving the waveform of a nearby small earthquake (used as an eGf) with a similar focal mechanism from the waveform of the larger target earthquake. Note that the resulting MRF is then normalized for finite-source modeling by setting the area of the MRF to the scalar moment of the target event, where the scalar moment is independently obtained. This deconvolution approach is reasonable if the difference in magnitude between the target and eGf events is more than one unit of magnitude, in which it can be assumed that the moment rate of the eGf event is a Dirac delta function.

We first search for smaller earthquakes for individual target $M 3+$ earthquakes from the high-resolution doubledifference earthquake catalog from Waldhauser and Schaff (2008). We also examine a set of deconvolved waveforms from different eGf events because identifying appropriate small earthquakes as eGf events is one of the key aspects for the finite-source rupture inversion. We test waveforms 
from smaller earthquakes that occurred within $500 \mathrm{~m}$ of the target hypocenter horizontally and with no depth restriction, having magnitudes at least 1.0 unit smaller than the target earthquake. We examine 2-3 eGf events for each target $M 3+$ earthquake to identify an optimal eGf event that provides the highest signal-to-noise ratio on the deconvolved MRFs, as well as to ascertain the stability of the obtained MRF.

We use a water-level deconvolution approach to extract MRFs of the target earthquake (Clayton and Wiggins 1976). A $1 \%$ water level is used to stabilize the frequencydomain deconvolution. The time window used for the deconvolution mainly includes direct $\mathrm{S}$ waves (Fig. 2a) and starts at least $0.5 \mathrm{~s}$ after the direct $P$-wave arrival. The length of the time window ranges from 5 to $8 \mathrm{~s}$ depending on the distances between earthquakes and the stations. We separately obtain MRFs for individual components and stack all the available MRFs at each station to enhance the signal-to-noise ratio (Fig. 2b).

We find that the resulting MRFs of the $2013 M_{\mathrm{w}} 3.2$ Orinda earthquake display two clear peaks that suggest radiation complexity in the rupture process. By using waveforms from different eGf events, we confirm that these two peaks on MRFs are not due to the choice of eGf events (Fig. 3). For the remaining three target earthquakes, the MRFs are dominated by a single peak with durations ranging from 0.05 to $0.3 \mathrm{~s}$. To further explore the complexity of the $2013 M_{\mathrm{w}} 3.2$ Orinda earthquake, we plot the MRFs with the directivity parameter $\Gamma$ (e.g., Schwartz and Ruff 1985; Ammon et al. 2005) defined as

$\Gamma_{i}=\cos \left(\phi_{i}-\phi_{r}\right) / c$

where $\phi_{i}$ and $\phi_{r}$ are the azimuth of the $i$ th station from the epicenter and the rupture azimuth, respectively, and $c$ is the phase velocity $(3.4 \mathrm{~km} / \mathrm{s}$ for our application). As shown in Fig. 4, the second pulse appears to shift systematically to later times with an increase in the azimuth (i.e., negative $\Gamma$ ) relative to the direction $331^{\circ} \mathrm{N}$ (parallel to the strike of $\mathrm{HF}$ ) with $c=3.40 \mathrm{~km} / \mathrm{s}$. The linear move out of the second pulse suggests two distinct subevents involved in the rupture process that are spatially separated, rather than being due to two episodes of slip at the same location on the fault. The move out also indicates that the two subevents are aligned along an azimuth of $331^{\circ} \mathrm{N}$.

\section{Finite-source rupture inversion}

The MRFs can be backprojected onto the fault plane to determine the fault slip (Mori and Hartzell 1990; Mori 1993). The finite-source rupture inversion used in this paper is the same as those used in Dreger (1994) and Dreger (1997) where a complete description of the methodology can be found. We here briefly summarize the inversion (a) Station: MHDL Component: DP2

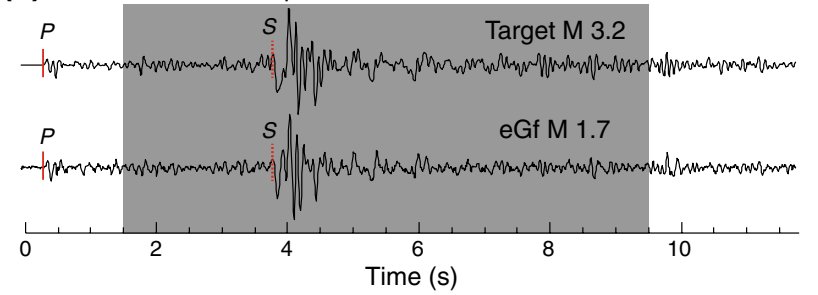

(b) Moment Rate Function (MRF)

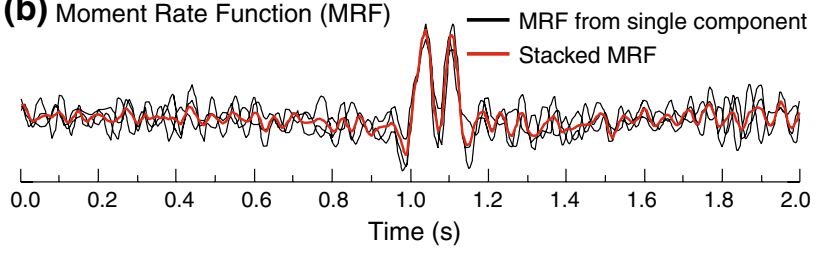

Fig. 2 a Horizontal component waveforms from station MHDL for the $2013 M_{\mathrm{w}} 3.2$ Orinda (target earthquake) and a $M 1.7$ eGf earthquakes are compared. Solid and dashed red lines indicate the arrival times of $P$ and $S$ phases, respectively. Waveforms in the time window shown by gray area $(8 \mathrm{~s})$ were used to determine the moment rate function (MRF). The distance between the target and eGf earthquakes is about $130 \mathrm{~m}$. b Black traces are deconvolved MRFs obtained for individual components. Also shown is the stacked MRF (red trace) for all available MRFs at this station

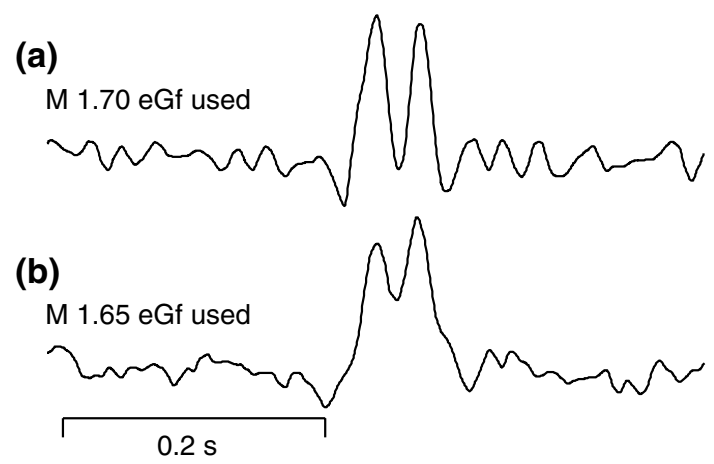

Fig. 3 Stacked moment rate functions for the $2013 M_{\mathrm{w}} 3.2$ Orinda (target earthquake) obtained from waveforms collected at station MHDL with a $M 1.7 \mathrm{eGf}$ and $\mathbf{b} M 1.65$ eGf earthquakes. The two pulses are recovered from both eGf earthquakes. The locations of these two eGf earthquake are $\sim 200 \mathrm{~m}$ apart from each other. The distances from the $2013 M_{\mathrm{w}} 3.2$ Orinda earthquake are about 130 and $350 \mathrm{~m}$ for the $M 1.7$ and $M 1.65$ eGf earthquakes, respectively

method with the data set for the $2013 M_{\mathrm{w}} 3.2$ Orinda earthquake as an example, in order to illustrate the steps involved in our finite-source modeling. Following Dreger (1994), we invert the MRFs to obtain the spatial distribution of fault slip. We assume that the source nucleates at a single point on the fault surface and that slip is propagates over the fault plane with a constant rupture velocity. At individual points on the fault, the slip occurs over a finite dislocation rise time with a slip velocity function. A boxcar function is assumed as the slip velocity function. 
(a)

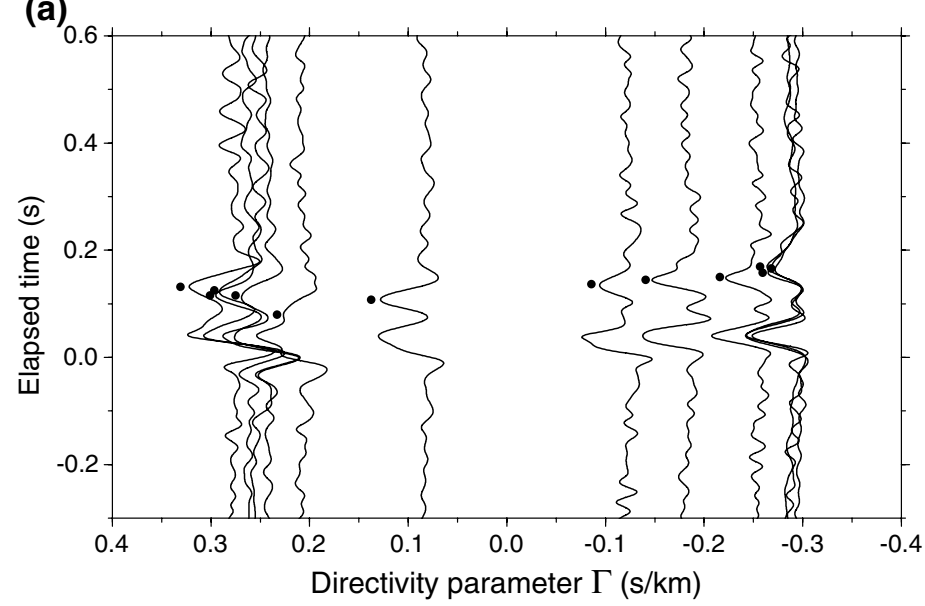

(b)

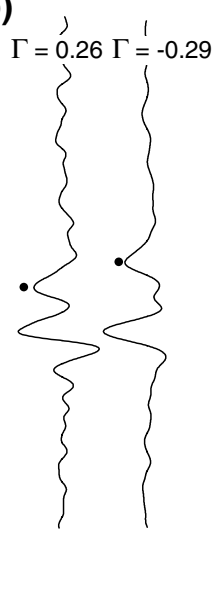

Fig. 4 a Moment rate functions for the $2013 M_{\mathrm{w}} 3.2$ Orinda earthquake plotted as a function of directivity parameter $\Gamma$, assuming a rupture azimuth of $331^{\circ} \mathrm{N}$ with a phase velocity of $3.4 \mathrm{~km} / \mathrm{s}$. Moment rate functions are aligned by the onset of the first pulse. A positive value of $\Gamma$ indicates station azimuth along the rupture direction. Black

For the inversion, we define the fault surface as a single $1 \mathrm{~km} \times 1 \mathrm{~km}$ plane and divide it into $96132 \times 32 \mathrm{~m}$ subfaults. The MRFs were interpolated to $1 \mathrm{kHz}$ to enable a fine-scale kinematic rupture process in the model. The interpolation does not change the shape of the moment rate functions. We employ a nonnegative least-squares algorithm of Lawson and Hanson (1974) to ensure slip positivity, and apply a spatial smoothing with a constant smoothing factor. For each target HF earthquake, we test the two fault planes corresponding to the two nodal planes inferred from the moment tensor analysis that was obtained from inversion of long-period (50-10 s) complete waveforms. To ascertain the best nodal plane, the variance reduction (VR) defined as (Dreger et al. 2007) is used;

$\mathrm{VR}=\left[1-\frac{\int\{d(t)-s(t)\}^{2} \mathrm{~d} t}{\int\{d(t)\}^{2} \mathrm{~d} t}\right] \times 100$

where $d$ and $s$ are the time series of the observed and synthetic MRFs, respectively. The preferred fault plane for each target $\mathrm{HF}$ earthquake is determined by maximizing VR (Fig. 5).

A grid-search approach is used to identify an optimal combination of rupture velocity, dislocation rise time, and smoothing factor. We test rupture velocity and dislocation rise time ranging from 1.55 to $3.40 \mathrm{~km} / \mathrm{s}$ and 0.005 to $0.2 \mathrm{~s}$, respectively (Fig. 6a). An optimal smoothing factor is determined from a trade-off curve between the data misfit and model roughness (inverse of smoothing factor) shown in Fig. 6b. After we obtain an optimal combination of model parameters that provides a maximum $V R$, we dots indicate the peak of the second pulse. b Two selected moment rate functions from stations with positive and negative $\Gamma$ to illustrate the decrease in differential time between the two pulses with an increase in $\Gamma$

then address the uncertainty in fault slip at each subfault with a Jackknife approach similar to Hartzell et al. (2007). The finite-source rupture inversion is repeated with different subsets of stations obtained by deleting about onethird of the total stations for each subset. The median and standard deviation at each subfault are estimated based on the distributions of fault slip determined from the repeated inversions. The coefficient of variation (COV) is then determined by estimating the ratio of standard deviation to the median slip (Fig. 7). A low COV implies less uncertainty of fault slip obtained for the subfaults.

\section{Results}

Our finite-source rupture inversion yields high VRs (94$99 \%$ ) for all target HF earthquakes analyzed in this study (Table 2). The rupture velocities obtained range from 2.15 to $3.15 \mathrm{~km} / \mathrm{s}$ correspond to $63-93 \%$ of the $S$-wave velocity $(3.4 \mathrm{~km} / \mathrm{s})$ near the hypocenters. For the four target HF earthquakes, we tested the two nodal planes and found that larger VRs are obtained for southwest dipping nodal planes that are parallel to the strike of the HF. We additionally tested a larger fault plane with $2 \mathrm{~km} \times 2 \mathrm{~km}$ for the finite-source rupture inversion and confirm that the resultant slip distributions do not alter significantly. Through the trade-off analysis, we find that a range of smoothing factors between 100 and 300 is appropriate for all target $\mathrm{HF}$ earthquakes (Fig. 6 and Supplementary Figs. S1, S2 and S3). We have tested the sensitivity of the slip models to the smoothing factor in this range and have confirmed that the 


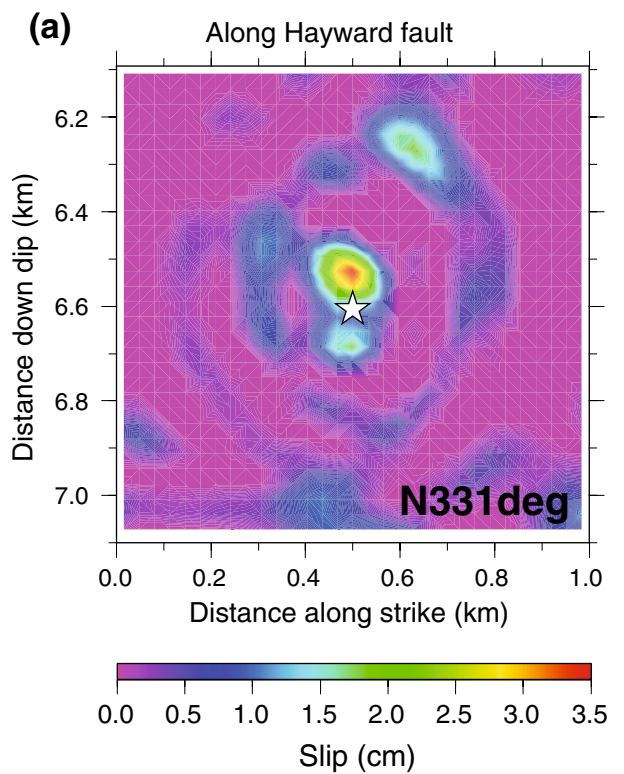

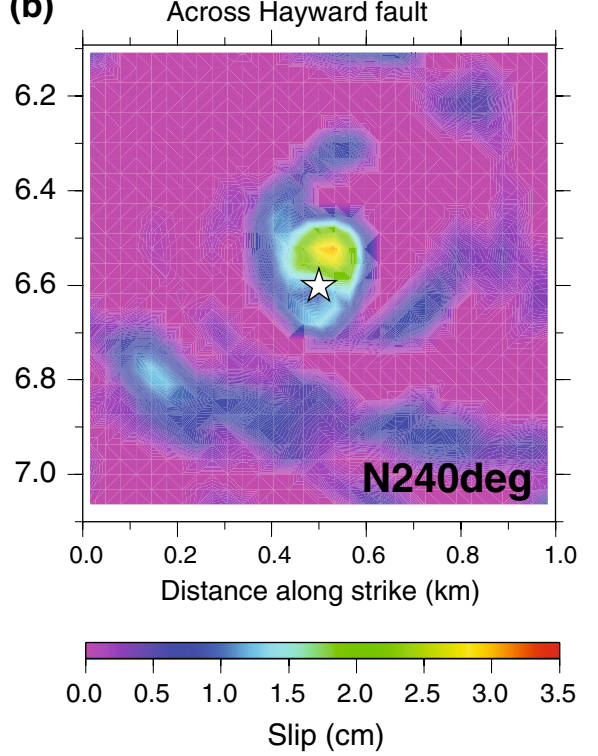

(c)

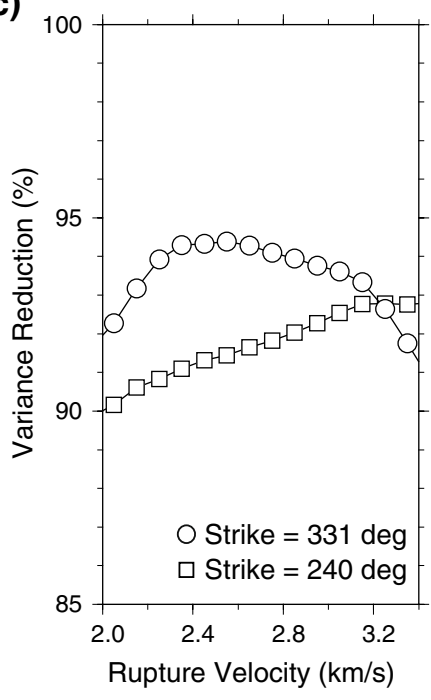

Fig. 5 Sensitivity test of fault planes for the $2013 M_{\mathrm{w}} 3.2$ Orinda earthquake. Spatial distributions of fault slip with the rupture azimuth of a $331^{\circ} \mathrm{N}$ (along the Hayward fault) and b $240^{\circ} \mathrm{N}$ (across the Hayward fault) are compared, where the star is the hypocenter of the $M_{\mathrm{w}}$ 3.2 Orinda earthquake. For these slip distribution estimates, a rupture velocity of $2.55 \mathrm{~km} / \mathrm{s}$, a rise time of $0.02 \mathrm{~s}$, and a smoothing factor of 200 were used. c The variance reduction as a function of rupture velocity is shown. Circles and squares are the resultant variance reductions for the slip models with rupture azimuths of $331^{\circ} \mathrm{N}$ and $240^{\circ} \mathrm{N}$, respectively (a)

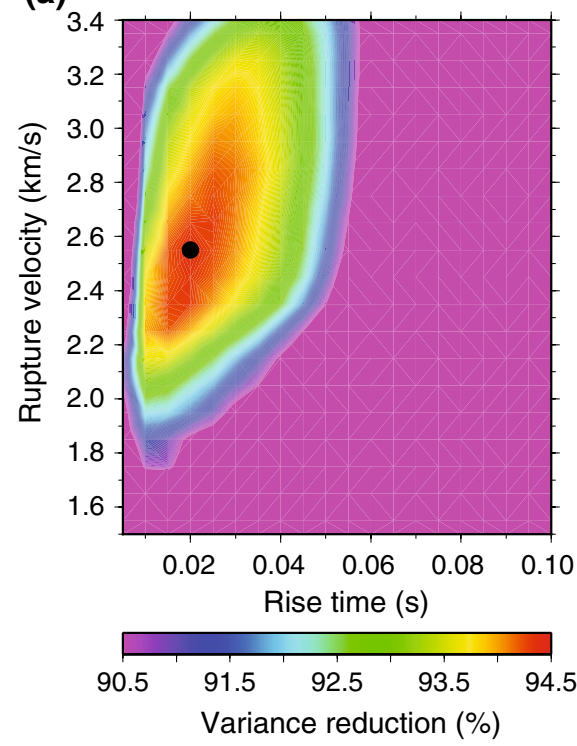

(b)

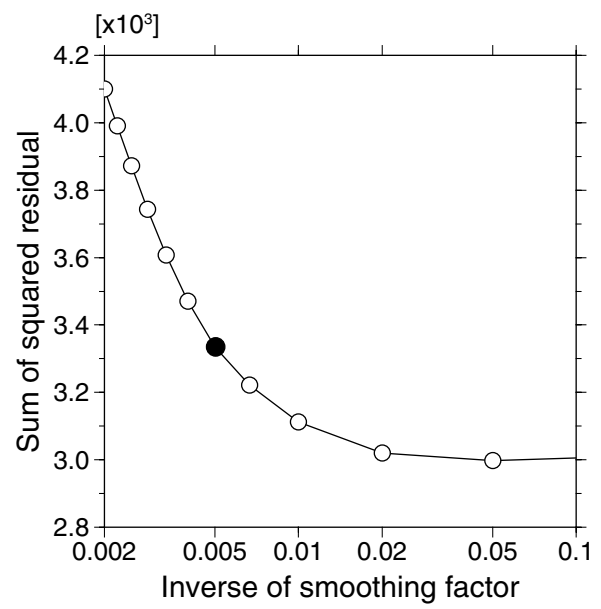

and rise time in which the variance reduction reaches its maximum. b Sum of squared residual between synthetic and observed moment rate functions as a function of inverse of smoothing factor with the optimal combination of rupture velocity and rise time (the solid circle shown in a). The smoothing factor of 200 (or 0.005 for the inverse of smoothing factor) shown as solid circle is selected from this trade-off curve 
(a)

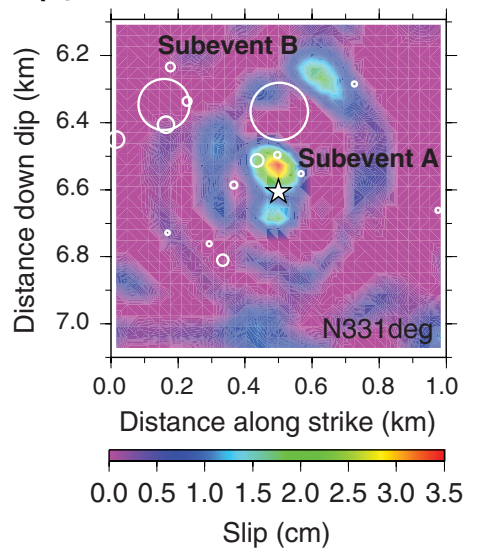

(b)

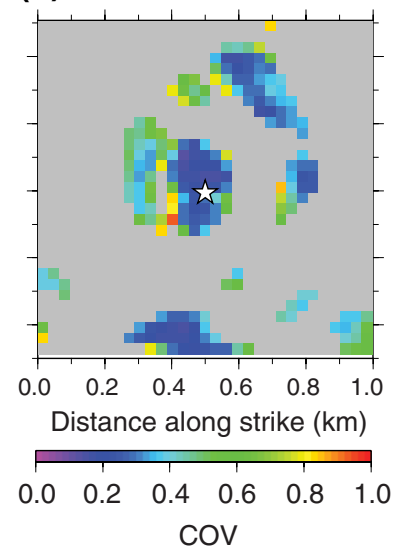

(c)

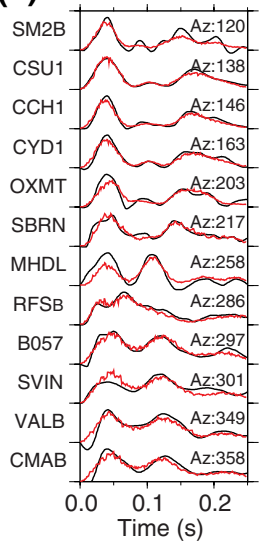

Fig. 7 Spatial distributions of $\mathbf{a}$ fault slip and $\mathbf{b}$ coefficient of variation (COV) for the $2013 M_{\mathrm{w}} 3.2$ Orinda earthquake in which the star is the hypocenter. The white circles are the aftershocks that occurred in the first 2 weeks after the $M_{\mathrm{w}} 3.2$ Orinda mainshock. The rupture sizes are estimated by a circular crack model (Eshelby 1957) with a 10 MPa stress drop. c Observed (black traces) and synthetic (red traces) moment rate functions used to determine the slip distribution. Also shown are the azimuths $(\mathrm{Az})$ in degrees from north from the hypocenter for individual stations

Table 2 Rupture models of Hayward-fault target earthquakes

\begin{tabular}{|c|c|c|c|c|c|c|c|c|c|}
\hline \multirow[t]{2}{*}{ Event } & \multirow[t]{2}{*}{ Rise time (s) } & \multirow{2}{*}{$\begin{array}{l}\text { Rupture velocity } \\
(\mathrm{km} / \mathrm{s})\end{array}$} & \multirow{2}{*}{$\begin{array}{l}\text { Smoothing } \\
\text { factor }\end{array}$} & \multirow[t]{2}{*}{$\operatorname{VR}(\%)$} & \multirow{2}{*}{$\begin{array}{l}\text { Peak/mean } \\
\text { slip (cm) }\end{array}$} & \multirow{2}{*}{$\begin{array}{l}\text { Peak/mean } \\
\text { stress drop }(\mathrm{MPa})\end{array}$} & \multicolumn{3}{|c|}{ Mechanism } \\
\hline & & & & & & & Strike & Dip & Rake \\
\hline BK11 & 0.020 & 2.15 & 200 & 95 & $41 / 13$ & $131 / 42$ & 144 & 81 & 1 \\
\hline $\mathrm{EC} 12$ & 0.055 & 3.15 & 200 & 99 & $45 / 19$ & $105 / 41$ & 147 & 83 & -170 \\
\hline OR13-1 & 0.015 & 3.05 & 200 & 96 & $5.1 / 2.0$ & $22 / 10$ & 327 & 90 & 175 \\
\hline OR13-2 & 0.020 & 2.55 & 200 & 94 & $3.4 / 0.8$ & $18 / 4.1$ & 331 & 85 & -171 \\
\hline
\end{tabular}

resultant rupture extent as well as peak and average slips do not change significantly. A smoothing factor of 200 is used to document the rupture process for all target earthquakes.

We first summarize the slip distributions for the two $M \sim 3$ Orinda earthquakes. The first Orinda earthquake with $M_{\mathrm{w}}$ of 3.0 occurred on October 7, 2013, at a depth of about $6.5 \mathrm{~km}$. Subsequently, the $M_{\mathrm{w}} 3.2$ Orinda earthquake occurred $380 \mathrm{~m}$ southeast of the first $M_{\mathrm{w}} 3.0$ Orinda earthquake. The $M_{\mathrm{w}} 3.2$ Orinda event appears to have a more complex rupture process as indicated by the MRFs (Fig. 4), where the slip distribution shows two distinct subevents (Fig. 7). A total of 12 stations were used to estimate the finite-source kinematic model and provides excellent station azimuth coverage. Using a grid-search approach, we found that a combination of rise time of $0.02 \mathrm{~s}$ and rupture velocity of $2.55 \mathrm{~km} / \mathrm{s}$ provides the maximum variance reduction (94\%) for the $2013 M_{\mathrm{w}} 3.2$ Orinda earthquake. The rise time is approximately $10 \%$ of the total source duration as defined by the MRF, which is consistent with the propagating slip-pulse model that Heaton (1990) found for larger magnitude earthquakes. In fact, the rise time scaling, inferred slip velocities of $0.1-4.0 \mathrm{~m} / \mathrm{s}$, and the rupture velocity of this earthquake are all consistent with what has been found for larger magnitude earthquakes (e.g., Heaton 1990; Mai and Beroza 2000) and in dynamic models of earthquake rupture (e.g., Day et al. 1998; Peyrat et al. 2001).

The first subevent (subevent A) located near the hypocenter of this earthquake (depth of $6.5 \mathrm{~km}$ ), and the other subevent (subevent B) located about $100 \mathrm{~m}$ northwest from the hypocenter at a depth of $6.2 \mathrm{~km}$. The peak slips of the subevents A and B are 3.4 and $1.8 \mathrm{~cm}$, respectively. We define the areas of the subevents in which the slip exceeds $10 \%$ of its peak slip and estimate the seismic moments assuming that rigidity of $31 \mathrm{GPa}$ derived from the one-dimensional GIL7 velocity model (Dreger and Romanowicz 1994) at the focal depth. The estimated seismic moments for the subevents $\mathrm{A}$ and $\mathrm{B}$ are $2.6 \times 10^{13}$ and $1.2 \times 10^{13} \mathrm{~N} \mathrm{~m}$, respectively, which are equivalent to 43 and $18 \%$ of the total seismic moment $\left(6.7 \times 10^{13} \mathrm{~N} \mathrm{~m}\right)$ obtained through the finite-source modeling. In contrast, the slip distribution of the $M_{\mathrm{w}} 3.0$ Orinda earthquake is characterized by failure of a single $0.05 \mathrm{~km}^{2}$ asperity with a maximum slip of $5 \mathrm{~cm}$ (Fig. 8) inferred from $11 \mathrm{MRFs}$. The high slip area is located immediately down-dip from the hypocenter. We identify an optimal combination of rise 
Fig. 8 Same as Fig. 7, except for the $2013 M_{\mathrm{w}} 3.0$ Orinda earthquake (a)

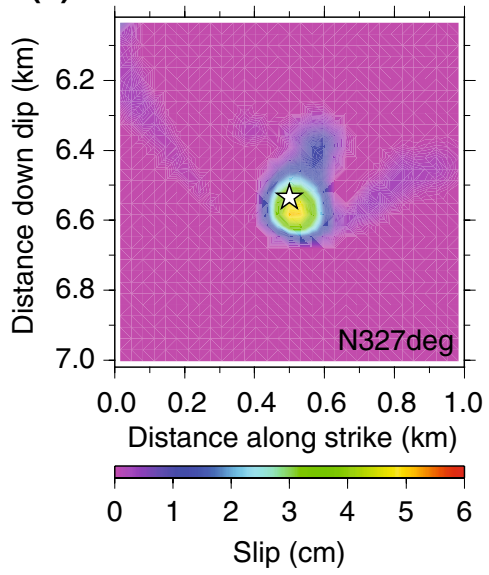

(a)

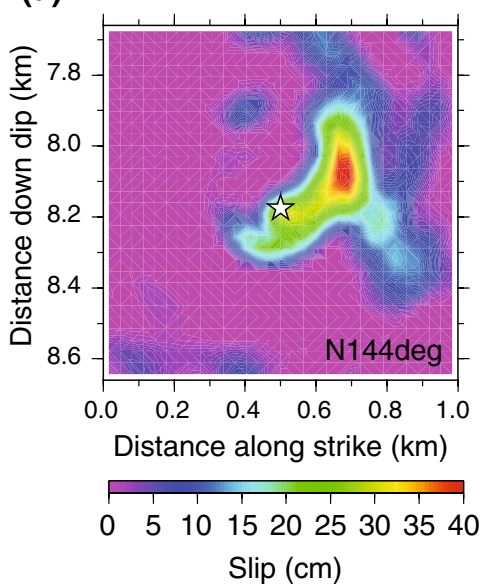

(a)

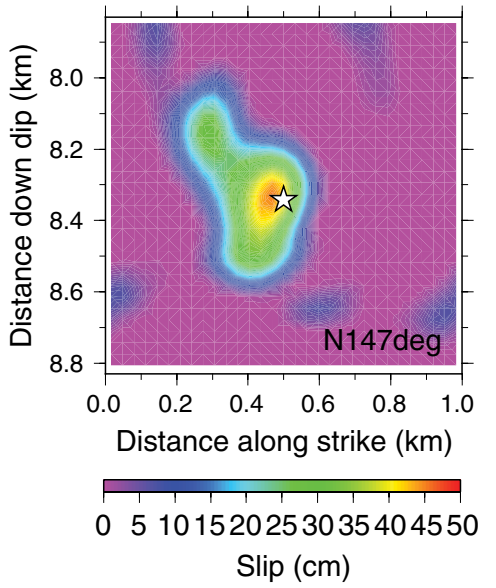

(b)

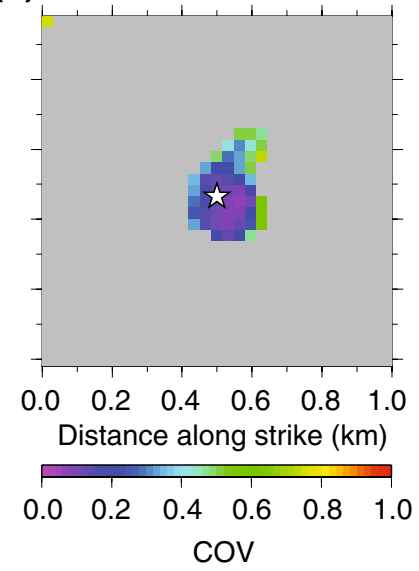

(c)

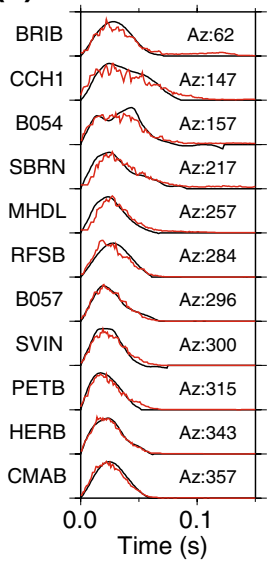

(b)

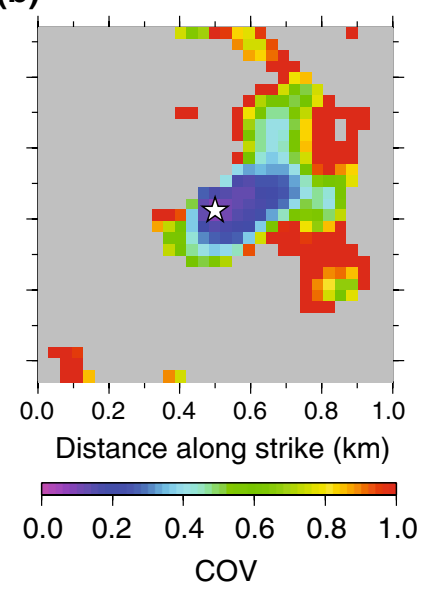

(c)

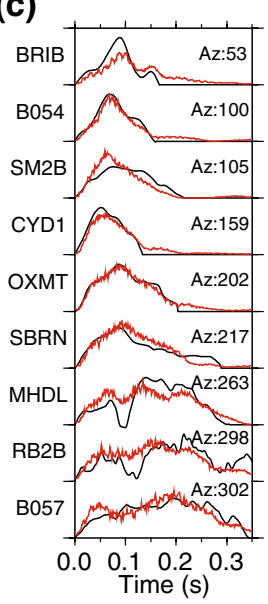

(b)

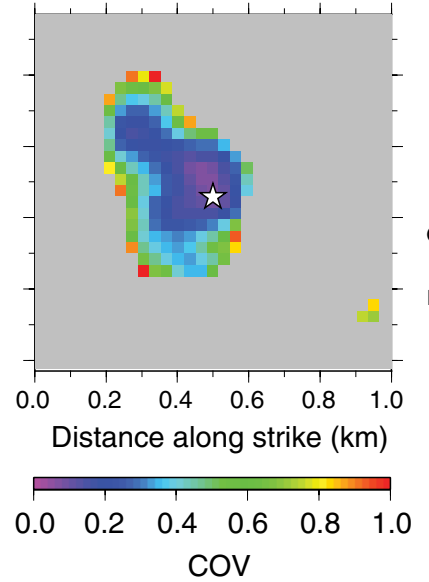

(c)

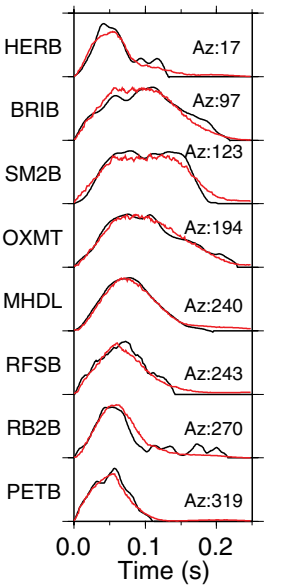

time $=0.015 \mathrm{~s}$ and rupture velocity $=3.05 \mathrm{~km} / \mathrm{s}$ for the $2013 M_{\mathrm{w}} 3.0$ Orinda earthquake (Supplementary Fig. S1).

Our inversion suggests strong directivity of rupture propagation for the remaining two HF earthquakes, the October 20, 2011, $M_{\mathrm{w}} 4.0$ Berkeley and the March 5, 2012,
$M_{\mathrm{w}} 4.0 \mathrm{El}$ Cerrito earthquakes. The southeast and northwest directivity are identified for the 2011 Berkeley and $2012 \mathrm{El}$ Cerrito earthquakes, respectively (Figs. 9, 10). Additionally, both earthquakes have notable up-dip rupture propagation. Nine and eight MRFs were used to determine the slip 
distributions of the Berkeley and El Cerrito earthquakes, respectively. Boatwright (2007) and Seekins and Boatwright (2010) also reported on rupture directivity using the peak ground velocity/acceleration measurements. The rupture directivities for the Berkeley and El Cerrito earthquakes inferred from the finite-source modeling are consistent with those reported by U.S. Geological Survey from the peak ground velocity observations (e.g., http://earthquake.usgs.gov/regional/nca/rupture/?id=20111020-1441 and http://earthquake.usgs.gov/regional/nca/rupture/?id= 20120305-0533).

The 2011 Berkeley earthquake has two high slip areas: One is located near the hypocenter at a depth of $8.2 \mathrm{~km}$ and the other is located $100 \mathrm{~m}$ shallow from the hypocenter. The amplitudes of both high slip areas are about 31 and $41 \mathrm{~cm}$, respectively. A rise time of $0.020 \mathrm{~s}$ and rupture velocity of $2.15 \mathrm{~km}$ were obtained through a grid-search approach (Supplementary Fig. S2). The 2012 El Cerrito earthquake is also characterized by high fault slip of $45 \mathrm{~cm}$ that is located near the hypocenter at a depth of $8.3 \mathrm{~km}$. In addition to the up-dip rupture, our analysis also suggests a fault slip of $30 \mathrm{~cm}$ immediately below the hypocenter down to $8.6 \mathrm{~km}$. We obtain a rise time of $0.055 \mathrm{~s}$ and a rupture velocity of $3.15 \mathrm{~km} / \mathrm{s}$ for the El Cerrito earthquake (Supplementary Fig. S3).

\section{Discussion}

As shown in Fig. 7, there is a complex rupture for the $2013 M_{\mathrm{w}} 3.2$ Orinda earthquake that involves two subevents. Through the Jackknife approach, we confirm that the uncertainties in fault slip on those two subevent areas are low $(\mathrm{COV}<0.3)$ (Fig. 7b). Our inversion suggests that subevent $\mathrm{B}$ occurred when the rupture front arrives at the nucleation point for subevent $\mathrm{B}$ with a rupture velocity of $2.55 \mathrm{~km} / \mathrm{s}$, based on the delay time between the two pulses observed on the MRFs. Another possible hypothesis is that dynamic triggering from seismic waves radiated by subevent A triggered subevent B. This hypothesis is, however, ruled out because the sensitivity analysis indicates that the rupture velocity should range from 2.4 to $2.8 \mathrm{~km} / \mathrm{s}$ (about $70-80 \%$ of the $S$-wave velocity) to fit the two pulses of MRFs (Fig. 6a), which is in the range of typical rupture velocities that have been found from kinematic source models reported in the literature (Somerville et al. 1999; Mai and Beroza 2000).

With the kinematic fault slip model obtained through the finite-source rupture inversion, we determine the spatial distributions of static stress drop for the HF target earthquakes, by using a method of Ripperger and Mai (2004). As shown in Fig. 11a, a spatially variable stress drop is obtained for the $2013 M_{\mathrm{w}} 3.2$ Orinda earthquake rupture (a)

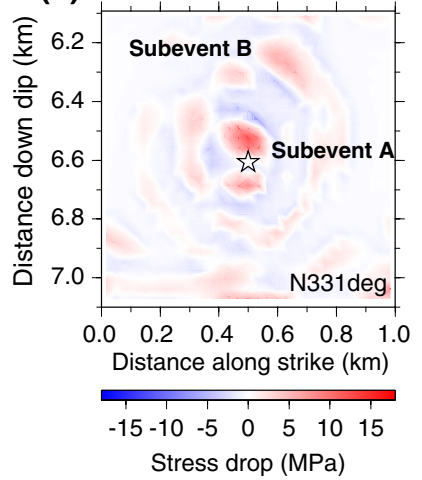

(c)

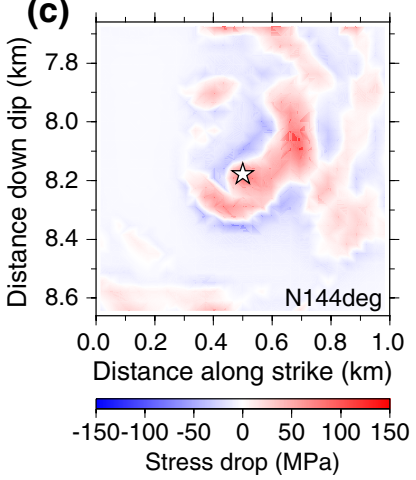

(b)

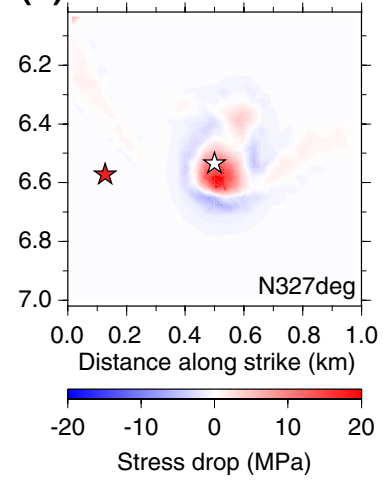

(d)

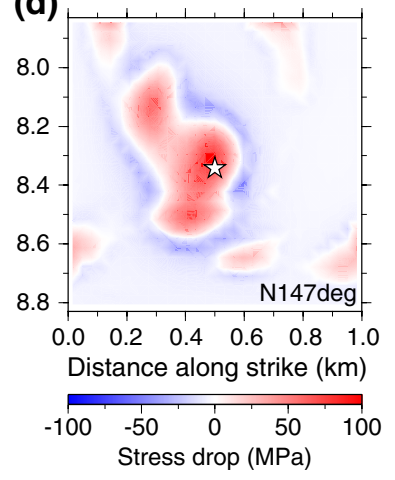

Fig. 11 Spatial distributions of stress drop for a the $2013 M_{\mathrm{w}} 3.2$ Orinda earthquake, b the $2013 M_{\mathrm{w}} 3.0$ Orinda earthquake, $\mathbf{c}$ the 2011 $M_{\mathrm{w}} 4.0$ Berkeley earthquake, and $\mathbf{d}$ the $2012 M_{\mathrm{w}} 4.0$ El Cerrito earthquake. The open stars are the locations of the target earthquakes. The red star shown in $\mathbf{b}$ is the hypocenter of the $2013 M_{\mathrm{w}} 3.2$ Orinda earthquake

area. The peak static stress drops for subevents A and B are comparable and are determined to be 18 and $8 \mathrm{MPa}$, respectively.

A total of 17 aftershocks were detected within 2 weeks following the $2013 M_{\mathrm{w}} 3.2$ Orinda earthquake by the NCSS. Interestingly, the largest $M 2.5$ aftershock occurred $\sim 1 \mathrm{~h}$ after the mainshock seems to have filled in the spatial gap between the two subevents (Fig. 7a). We also visually examined continuous borehole records and were able to identify several aftershocks that are not listed in the NCSS earthquake catalog, suggesting the potential for obtaining even detail and understanding of the earthquake process using the borehole data.

The $2013 M_{\mathrm{w}} 3.0$ Orinda earthquake has a quasi-circular rupture near the hypocenter. The resultant stress drop distribution has a maximum stress drop of $22 \mathrm{MPa}$. We define the effective rupture area by calculating the total area of the subfaults where fault slip exceeds $10 \%$ of the peak slip. The mean static stress drop of $10 \mathrm{MPa}$ is obtained over the effective rupture area for the $2013 M_{\mathrm{w}} 3.0$ Orinda earthquake (Fig. 11b). We also explore possible triggering of the $2013 M_{\mathrm{w}} 3.2$ Orinda earthquake by the $M_{\mathrm{w}} 3.0$ Orinda 
earthquake that occurred 1 week earlier, by computing the static stress change $(\Delta \sigma)$ (Aki and Richards 1980):

$\Delta \sigma=\left(\frac{1}{6 \pi}\right) \frac{\Delta \bar{\sigma}_{\mathrm{s}}}{(r / L)^{3}}$,

where $\Delta \bar{\sigma}_{\mathrm{s}}$ is the mean stress drop; $r$ and $L$ is the distance away from the $M_{\mathrm{w}} 3.0$ Orinda rupture and the length of the coseismic rupture, respectively. With the mean static stress drop of $10 \mathrm{MPa}$ inferred from our inversion, we find the static stress change in an order of $1 \mathrm{MPa}$ at the hypocenter of the $2013 M_{\mathrm{w}} 3.2$ Orinda earthquake, suggesting that the $M_{\mathrm{w}} 3.2$ could have been triggered by the earlier event. This level of static stress change is more than 10 times larger than the minimum threshold for triggering of earthquakes (e.g., Stein 1999).

Both Orinda earthquakes occurred $\sim 5 \mathrm{~km}$ northeast of the surface trace of the HF (Fig. 1) in a region where there is notable off-HF seismicity, although the activity is lower than that along the adjacent segment of the HF. In 1977, an earthquake swarm occurred around the locations of the Orinda earthquakes (Bolt et al. 1977). This seismicity would be an indication of off-fault deformation that may be caused by the HF system. By comparing the geodetically imaged fault slip rate and seismicity, Shirzaei and Bürgmann (2013) suggest that off-fault micro-earthquake activity represents an indirect indicator of the degree of creeping and locking of faults. For example, the seismicity will be highly localized near the fault interface along creeping segments. Inversion of geodetic and repeating earthquake data along the portion of the HF adjacent to the Orinda seismicity shows the HF to be creeping at shallow depths $(<\sim 5 \mathrm{~km})$ with about $7 \mathrm{~mm} /$ year and have both portions of creeping and locked fault at greater depths (Schmidt et al. 2005).

Our study reveals a spatial heterogeneity of the earthquake stress drop off the main fault trace, and the peak stress drops that were obtained indicate a higher applied shear stress. Our preferred interpretation is that either the higher frictional strength of the crust or greater geometrical complexity is responsible for the high level of the applied shear stress that we obtained. However, it should be noted that Hardebeck and Aron (2009) pointed out that the spatial correlation between the strength of the wall rock and earthquake stress drops is not evident for events in the HF zone. Another interpretation is that the high-applied shear stress results from the cumulative aseismic slip difference between the locked and creeping portions of the HF.

The $2011 M_{\mathrm{w}} 4.0$ Berkeley and $2012 M_{\mathrm{w}} 4.0$ El Cerrito earthquakes are characterized by high stress drop (Fig. 11c, d). The peak and mean stress drops for those two earthquakes are about 100-130 and $40 \mathrm{MPa}$, respectively. Using a spectral method, Hardebeck and Aron (2009) also identified high-stress-drop earthquakes (>100 MPa) near the rupture zones of the Berkeley and El Cerrito earthquakes.
As similar to the $M_{\mathrm{w}} 3.2$ Orinda earthquake, the finitesource inversion yields spatial heterogeneous distributions of stress drop for both the Berkeley and El Cerrito earthquakes, suggesting the spatial variability of the strength of fault. The high slips that were obtained represent more than 30 years of loading of the HF, assuming with the long-term slip rate of 3-5 mm/year (Schmidt et al. 2005).

For these two high-stress-drop earthquakes, we calculate the radiated seismic energy and radiation efficiency. Following Vassiliou and Kanamori (1982) and Kikuchi and Fukao (1988), the radiated seismic energy $\left(E_{\mathrm{s}}\right)$ is estimated through an integration of the square of the seismic moment acceleration function. We obtain the seismic moment acceleration function for the 2011 Berkeley and $2012 \mathrm{El}$ Cerrito earthquakes by a two-step approach: (1) estimating a median MRF by stacking all available MRFs and (2) scaling the median MRF by the scalar seismic moment of the eGf event. Our calculation yields an $E_{\mathrm{s}}$ of about $2.1-2.4 \times 10^{10} \mathrm{~J}$ for both earthquakes and a scaled energy $\widetilde{e}=E_{\mathrm{S}} / M_{0}$ of $\sim 1.6-1.9 \times 10^{-5}$. The resultant scaled energy is in good agreement with those obtained for $M_{\mathrm{w}} \sim 4$ earthquakes (Kanamori et al. 1993; Ide and Beroza 2001; Mori et al. 2003).

For the radiation efficiency $\left(\eta_{R}\right)$, we first calculate the elastic energy $\left(E_{T 0}\right)$ by using the equation $E_{T 0}=\frac{1}{2} \int \Delta \sigma_{\mathrm{s}} D A$ (Kanamori and Rivera 2006) where $\Delta \sigma_{\mathrm{s}}$ and $D$ are the stress drop and the fault slip at individual subfaults, respectively; $A$ is the area of the subfault. We obtain values for $E_{T 0}$ that are $7.6 \times 10^{11}$ and $8.7 \times 10^{11} \mathrm{~J}$ for the 2011 Berkeley and 2012 El Cerrito earthquakes, respectively. The radiation efficiency $\eta_{R}=E_{\mathrm{S}} / E_{T 0}$ is then estimated to be about 0.03 which suggests a very low radiation efficiency for those two earthquakes, compared with those obtained in Venkataraman and Kanamori (2004) where the resultant radiation efficiency for most earthquakes analyzed was found to be larger than 0.25 . Our result suggests that the majority of energy is dissipated during the earthquake rupture process.

The radiation efficiency is also proportional to the rupture velocity (e.g., Kanamori and Rivera 2006). A lower radiation efficiency yields lower rupture velocity. Our finite-source modeling finds 63 and $93 \%$ of the $S$-wave velocity for the 2011 Berkeley and 2012 El Cerrito earthquakes, respectively, which seems inconsistent with the low radiation efficiency inferred from the seismic radiated energy and elastic energy. It should be noted, however, that our inversion does not constrain the rupture velocity (and rise time) for those two earthquakes very well (Supplementary Figs S2 and S3). Lower rupture velocity $(\sim 1.5-1.8 \mathrm{~km} / \mathrm{s})$ still provides high variance reduction. Also possible is a scenario in which there is a spatial variability of rupture velocity, whereas our finite-source modeling assumes a constant rupture velocity throughout the growth 
of earthquake rupture. Hence, the inconsistency of radiation efficiency estimate may indicate that the rupture velocity varies during rupture process.

As shown in Fig. 11c, d, there are strong fault patches, with possible dimensions of a few tens of meters along the HF that appear to sustain shear stress up to $\sim 100 \mathrm{MPa}$. Near the 2011 Berkeley and 2012 El Cerrito earthquakes rupture zones, the spatial heterogeneity of the fault strength is also suggested by the distribution and relatively high activity of characteristically repeating micro-earthquakes (Bürgmann et al. 2000; Waldhauser and Ellsworth 2002; Schmidt et al. 2005; Shirzaei et al. 2013) that are thought to reflect strong small asperities surrounded by weak partially aseismically slipping fault (Johnson and Nadeau 2002). As discussed above, our finite-source modeling suggests that the failure of the strong patches for the 2011 Berkeley and 2012 El Cerrito earthquakes appears to be accompanied with notable non-radiated energy.

\section{Conclusions}

We examined the rupture process for recent HF microearthquakes using an empirical Greens' function finitesource modeling approach. With the availability of seismic recordings from an array of borehole stations, we are able to resolve a variety of rupture behaviors including subevents, directivity, and high stress drop. Our kinematic finitesource models reveal a complex slip distribution for the $2013 M_{\mathrm{w}} 3.2$ Orinda earthquake that is characterized by a patch of slip with a maximum slip of $3.4 \mathrm{~cm}$ concentrated near the hypocenter at about $6.5 \mathrm{~km}$ depth, with a large secondary patch of slip (peak slip of $1.8 \mathrm{~cm}$ ) centered up-dip and northwest from the hypocenter at a distance of about $400 \mathrm{~m}$ away. The resultant complex distribution of fault slip suggests strong heterogeneity of stress drop within the rupture interior.

We also obtained a slip model of the $2013 M_{\mathrm{w}} 3.0$ Orinda earthquake that occurred about 1 week before the $M_{\mathrm{w}} 3.2$ Orinda earthquake. We find a static stress drop of an order of $1 \mathrm{MPa}$ imparted by the $M_{\mathrm{w}} 3.0$ Orinda earthquake at the hypocenter of the $M_{\mathrm{w}} 3.2$ Orinda earthquake, which may indicate that it was triggered by the earlier earthquake.

High-peak (100-130 MPa) and mean ( 40 MPa) stress drops are obtained for the $2011 M_{\mathrm{w}} 4.0$ Berkeley and $2012 M_{\mathrm{w}} 4.0 \mathrm{El}$ Cerrito earthquakes. The high-stress-drop earthquakes suggest that strong fault patches exist on the HF. The spatial variability of the stress drop obtained indicates the heterogeneity of fault strength within the earthquake rupture zones. The estimates of seismically radiated energy and elastic energy suggest very low radiation efficiency ( 0.03) for the 2011 Berkeley and 2012 El Cerrito earthquakes, indicating that most energy in the earthquakes is dissipated during the growth of earthquake rupture.

Acknowledgments We thank A. Nayak and L. Ye for discussions. The comments from Marco Bohnhoff, an anonymous reviewer, and the Editor significantly improved the manuscript. Waveform data, metadata, and earthquake catalog for this study were accessed through the Northern California Earthquake Data Center (NCEDC 2014). The Berkeley Seismological Laboratory (BSL) and U.S. Geological Survey contributed this data to the NCEDC. A software package, Generic Mapping Tools (GMT) (Wessel and Smith 1998), was used for plotting figures. This study was supported by the U.S. Geological Survey through award G10AC00093 and by the California Department of Transportation through grant 59A0578. This is BSL Contribution Number 15-04.

Open Access This article is distributed under the terms of the Creative Commons Attribution 4.0 International License (http://creativecommons.org/licenses/by/4.0/), which permits unrestricted use, distribution, and reproduction in any medium, provided you give appropriate credit to the original author(s) and the source, provide a link to the Creative Commons license, and indicate if changes were made.

\section{References}

Aki K, Richards PG (1980) Quantitative seismology-theory and methods. W. H. Freeman, New York

Allmann BP, Shearer PM (2007) Spatial and temporal stress drop variations in small earthquakes near Parkfield, California. J Geophys Res 112:B04305. doi:10.1029/2006JB004395

Allmann BP, Shearer PM (2009) Global variations of stress drop for moderate to large earthquakes. J Geophys Res 114:B01310. doi: 10.1029/2008JB005821

Ammon CJ, Ji C, Thio H-K et al (2005) Rupture process of the 2004 Sumatra-Andaman earthquake. Science 308:1133-1139. doi:10.1126/science. 1112260

Baltay A, Ide S, Prieto G, Beroza G (2011) Variability in earthquake stress drop and apparent stress. Geophys Res Lett 38:L06303. doi:10.1029/2011GL046698

Boatwright J (2007) The persistence of directivity in small earthquakes. Bull Seismol Soc Am 97:1850-1861. doi:10.1785/0120050228

Bolt BA, Stifler J, Uhrhammer R (1977) The Briones Hills earthquake swarm of January 8, 1977, Contra Costa County, California. Bull Seismol Soc Am 67:1555-1564

Bürgmann R, Schmidt D, Nadeau RM et al (2000) Earthquake potential along the northern Hayward fault, California. Science 289:1178-1182. doi:10.1126/science.289.5482.1178

Chen X, Shearer PM (2011) Comprehensive analysis of earthquake source spectra and swarms in the Salton Trough, California. J Geophys Res 116:B09309. doi:10.1029/2011JB008263

Clayton RW, Wiggins RA (1976) Source shape estimation and deconvolution of teleseismic bodywaves. Geophys J Int 47:151-177. doi:10.1111/j.1365-246X.1976.tb01267.x

Day SM, Yu G, Wald DJ (1998) Dynamic stress changes during earthquake rupture. Bull Seismol Soc Am 88:512-522

Dreger DS (1994) Northridge, California earthquake. Geophys Res Lett 21:2633-2636. doi:10.1029/94GL02661

Dreger DS (1997) The large aftershocks of the Northridge earthquake and their relationship to mainshock slip and fault-zone complexity. Bull Seismol Soc Am 87:1259-1266

Dreger DS, Romanowicz B (1994) Source characteristics of events in the San Francisco Bay region. US Geol Surv Open File Rep 94-176:301-309 
Dreger DS, Nadeau RM, Chung A (2007) Repeating earthquake finite source models: strong asperities revealed on the San Andreas fault. Geophys Res Lett 34:L23302. doi:10.1029/2007GL031353

Eshelby JD (1957) The determination of the elastic field of an ellipsoidal inclusion, and related problems. Proc R Soc A Math Phys Eng Sci 241:376-396. doi:10.1098/rspa.1957.0133

Hardebeck JL, Aron A (2009) Earthquake stress drops and inferred fault strength on the Hayward fault, east San Francisco Bay, California. Bull Seismol Soc Am 99:1801-1814. doi:10.1785/0120080242

Hartzell S, Liu P, Mendoza C et al (2007) Stability and uncertainty of finite-fault slip inversions: application to the 2004 Parkfield, California, earthquake. Bull Seismol Soc Am 97:1911-1934. doi: $10.1785 / 0120070080$

Heaton TH (1990) Evidence for and implications of self-healing pulses of slip in earthquake rupture. Phys Earth Planet Inter 64:1-20. doi:10.1016/0031-9201(90)90002-F

Ide S, Beroza GC (2001) Does apparent stress vary with earthquake size? Geophys Res Lett 28:3349-3352. doi:10.1029/200 1 GL013106

Imanishi K, Ellsworth W (2006) Source scaling relationships of microearthquakes at Parkfield, CA, determined using the SAFOD pilot hole seismic array. In: Abercrombie RE, McGarr A, Di Toro G, Kanamori H (eds) Earthquakes radiated energy Phys. faulting, Am Geophys Union Monogr 170, pp 81-90

Johnson LR, Nadeau RM (2002) Asperity model of an earthquake: static problem. Bull Seismol Soc Am 92:672-686. doi:10.1785/0120000282

Kanamori H, Rivera L (2006) Energy partitioning during an earthquake. In: Abercrombie RE, McGarr A, Di Toro G, Kanamori H (eds) Earthquakes radiated energy Phys faulting, Am Geophys Union Monogr 170, pp 3-13

Kanamori H, Mori J, Hauksson E et al (1993) Determination of earthquake energy release and ML using TERRASCOPE. Bull Seismol Soc Am 83:330-346

Kikuchi M, Fukao Y (1988) Seismic wave energy inferred from longperiod body wave inversion. Bull Seismol Soc Am 78:1707-1724

Lawson CL, Hanson RJ (1974) Solving least squares problems. Prentice Hall, Englewood Cliffs

Lienkaemper JJ, McFarland FS, Simpson RW et al (2012) long-term creep rates on the Hayward fault: evidence for controls on the size and frequency of large earthquakes. Bull Seismol Soc Am 102:31-41. doi:10.1785/0120110033

Mai PM, Beroza GC (2000) Source scaling properties from finitefault-rupture models. Bull Seismol Soc Am 90:604-615. doi:10.1785/0119990126

McGarr A, Fletcher JB (2002) Mapping apparent stress and energy radiation over fault zones of major earthquakes. Bull Seismol Soc Am 92:1633-1646. doi:10.1785/0120010129

Mori J (1993) Fault plane determinations for three small earthquakes along the San Jacinto Fault, California: search for cross faults. J Geophys Res 98:17711-17722. doi:10.1029/93JB01229

Mori J, Hartzell S (1990) Source inversion of the 1988 Upland, California, earthquake: determination of a fault plane for a small event. Bull Seismol Soc Am 80:507-518

Mori J, Abercrombie RE, Kanamori H (2003) Stress drops and radiated energies of aftershocks of the 1994 Northridge, California, earthquake. J Geophys Res 108:2545. doi:10.1029/200 1JB000474

Murray MH, Bock Y, Bürgmann R et al (2002) Broadband observations of plate boundary deformation in the San Francisco Bay area. Am Geophys, Union Fall Meet
Nadeau RM, Johnson LR (1998) Seismological studies at Parkfield VI: moment release rates and estimates of source parameters for small repeating earthquakes. Bull Seismol Soc Am 88:790-814

NCEDC (2014) Northern California Earthquake Data Center. UC Berkeley Seismol Lab Dataset. doi: 10.7932/NCEDC

Peyrat S, Olsen K, Madariaga R (2001) Dynamic modeling of the 1992 Landers earthquake. J Geophys Res 106:26467. doi:10.10 29/2001JB000205

Ripperger J, Mai PM (2004) Fast computation of static stress changes on 2D faults from final slip distributions. Geophys Res Lett 31:L18610. doi:10.1029/2004GL020594

Schmidt DA, Bürgmann R, Nadeau RM, D'Alessio M (2005) Distribution of aseismic slip rate on the Hayward fault inferred from seismic and geodetic data. J Geophys Res 110:B08406. doi:10.1 029/2004JB003397

Schwartz SY, Ruff LJ (1985) The 1968 Tokachi-Oki and the 1969 Kurile Islands earthquakes: variability in the rupture process. J Geophys Res 90:8613. doi:10.1029/JB090iB10p08613

Seekins LC, Boatwright J (2010) Rupture directivity of moderate earthquakes in northern California. Bull Seismol Soc Am 100:1107-1119. doi:10.1785/0120090161

Shirzaei M, Bürgmann R (2013) Time-dependent model of creep on the Hayward fault from joint inversion of 18 years of InSAR and surface creep data. J Geophys Res Solid Earth 118:1733-1746. doi:10.1002/jgrb.50149

Shirzaei M, Bürgmann R, Taira T (2013) Implications of recent asperity failures and aseismic creep for time-dependent earthquake hazard on the Hayward fault. Earth Planet Sci Lett 371-372:5966. doi:10.1016/j.epsl.2013.04.024

Somerville P, Irikura K, Graves R et al (1999) Characterizing crustal earthquake slip models for the prediction of strong ground motion. Seismol Res Lett 70:59-80

Stein RS (1999) The role of stress transfer in earthquake occurrence. Nature 402:605-609. doi:10.1038/45144

Uchide T, Ide S (2010) Scaling of earthquake rupture growth in the Parkfield area: self-similar growth and suppression by the finite seismogenic layer. J Geophys Res 115:B11302. doi:10.1029/20 09JB007122

Uhrhammer RA, McEvilly TV (1997) Performance of a borehole network in an urban environment: the Hayward Fault Network. Seismolological Society of America Annual Meeting, Honolulu, Hawaii

Vassiliou MS, Kanamori H (1982) The energy release in earthquakes. Bull Seismol Soc Am 72:371-387

Venkataraman A, Kanamori H (2004) Observational constraints on the fracture energy of subduction zone earthquakes. J Geophys Res Solid Earth 109:B05302. doi:10.1029/2003JB002549

Waldhauser F, Ellsworth WL (2002) Fault structure and mechanics of the Hayward fault, California, from double-difference earthquake locations. J Geophys Res 107:2054. doi:10.1029/200 0JB000084

Waldhauser F, Schaff DP (2008) Large-scale relocation of two decades of northern California seismicity using cross-correlation and double-difference methods. J Geophys Res 113:B08311. doi :10.1029/2007JB005479

Wessel P, Smith WHF (1998) New, improved version of generic mapping tools released. EOS Trans Am Geophys Union 79:579. doi:10.1029/98EO00426

Yamada T, Mori J, Ide S et al (2005) Radiation efficiency and apparent stress of small earthquakes in a south African gold mine. J Geophys Res 110:B01305. doi:10.1029/2004JB003221 